\title{
Effect of Processing Parameters on Microstructure and Tensile Properties of Austenitic Stainless Steel 304L Made by Directed Energy Deposition Additive Manufacturing
}

\author{
Zhuqing Wang ${ }^{\mathrm{a}}$, Todd A. Palmer ${ }^{\mathrm{a}, \mathrm{b}}$, Allison M. Beese, \\ ${ }^{a}$ Department of Materials Science and Engineering, Pennsylvania State University, University \\ Park, PA, 16802, USA \\ ${ }^{\mathrm{b}}$ Applied Research Laboratory, Pennsylvania State University, University Park, PA, 16802, USA \\ *Corresponding author email: amb961@ psu.edu
}

\begin{abstract}
The effect of processing parameters on the mechanical properties of AISI 304L stainless steel components fabricated using laser-based directed energy deposition additive manufacturing (AM) was investigated. Two walls were fabricated, with high linear heat inputs of 271 and 377 $\mathrm{J} / \mathrm{mm}$, to determine the effect of processing parameters on microstructure and mechanical properties of 304L made by AM. Uniaxial tension tests were performed on samples extracted from the walls in longitudinal and transverse directions. The yield strength, ultimate tensile strength, and ductility, were higher in the lower linear heat input wall compared to the higher linear heat input wall. The ductility in the longitudinal direction was less than that in the transverse direction, while there was no clear anisotropy in strength. A grain growth model adapted from welding was used to interpret and predict the grain sizes in the walls as a function of processing parameters and position. A Hall-Petch relationship was used to explain the effect of local grain size and morphology on the location- and direction-dependent yield strengths in
\end{abstract}


each wall. The ultimate tensile strengths and elongations of the material made by AM were less than those of annealed 304L plate since a microstructural phase transformation from austenite to martensite, which provides a mechanism for significant macroscopic strain hardening, occurred in the annealed material, but not the material made by AM. Chemical analysis showed that walls made by AM had higher nitrogen content, which stabilizes the austenitic phase, than the annealed plate.

Keywords: Additive manufacturing, austenitic stainless steel, mechanical behavior, microstructure, grain growth 


\section{Introduction}

In additive manufacturing (AM) of metallic alloys, 3-dimensional components are fabricated in a layer-by-layer fashion by the local delivery of metal wire or powder feedstock, the melting of the feedstock by a laser or electron beam heat source, and the solidification of the molten material, which fuses to the layer below [1-3]. Two classes of laser-based AM with powder feedstock are powder bed fusion (PBF), in which a thin layer of metal powder is spread in a reservoir and melted selectively by a laser beam, and directed energy deposition (DED), in which the powder is delivered by a nozzle or nozzles to the molten pool generated beneath the laser scanning beam [1].

The microstructures and therefore the mechanical properties of AM components are largely influenced by processing parameters, including laser power, scanning speed, and powder feed rate. Each location in the component being built is subjected to a complex thermal history as the material first undergoes a rapid solidification, and then is heated and cooled with each additional layer. These complex thermal cycles can create heterogeneous and anisotropic microstructures that differ from traditional wrought counterparts. In addition, gas entrapment pores and lack of fusion defects are frequently formed during AM, which can be detrimental to the mechanical properties, and particularly ductility, of the component $[4,5]$.

The present work focuses on the microstructure and mechanical properties of AISI type 304L austenitic stainless steel produced by DED. Austenitic stainless steels, such as AISI types 301, 304, and 316 have high strength and ductility and good corrosion resistance [6,7]. These materials have the potential to undergo deformation-induced phase transformation from a facecentered cubic (fcc) austenitic phase to a body-centered cubic (bcc) martensitic phase when 
subjected to plastic deformation [8-14]. This microstructural transformation is of interest as it results in a high rate of strain hardening on the macroscale [15-17].

Previous research on AISI type 316, 316L, and 304 stainless steel components made by DED shows that the uniaxial tensile strength is lower but elongation higher in samples loaded along the transverse direction, or parallel to the vertical build direction, as compared with longitudinal samples, or those whose tensile axis is aligned with subsequent layers [2,18-20]. Zhang et al. [20] studied the effect of laser power and scanning speed on microstructure and mechanical properties by building stainless steel 316 components by DED with laser powers ranging from $600 \mathrm{~W}$ to $1400 \mathrm{~W}$ and scanning speeds ranging from $2 \mathrm{~mm} / \mathrm{s}$ to $10 \mathrm{~mm} / \mathrm{s}$. They showed that yield and tensile strengths decreased with increasing laser power and decreasing scanning speed, as this combination results in slower cooling rates and therefore larger grains.

A summary of mechanical properties of austenitic stainless steel components made by AM, compared with wrought plate, is given in Table 1. The mechanical properties of components made by AM vary in the literature as the process parameters vary between studies. While no single parameter can fully describe the thermal history of the component, we compute the linear heat input, defined as the laser power divided by the laser scanning speed, when available for the studies in Table 1 as a metric for comparison of the thermal history variation between studies. This table shows that in general, components made by AM have higher yield and tensile strengths, than wrought materials of the same stainless steel alloy, with the measured elongations in AM having a wide variation between studies.

In the present work, the effect of processing parameters on the microstructure and tensile mechanical properties of AISI type 304L stainless steel fabricated by laser-based DED was investigated through both experimental characterization and the application of grain growth and 
grain size strengthening models. In particular, as the need arises for large structures to be fabricated by DED, higher deposition rates, corresponding to higher heat inputs and laser powers, will be required. However, little is known about what impact high linear heat inputs have on the microstructure and mechanical properties of these large builds as prior work has focused on small builds of AISI type 304, 316, or 316L stainless steel. By examining relatively high heat inputs compared to what has been previously reported, and the influence of varying linear heat input on microstructure and mechanical properties, the role of less severe solidification and cooling rates in AM on the mechanical properties of components was examined. By interpreting the experimental data through the application of existing processingstructure and structure-property models, a quantitative connection among processing, structure, and mechanical properties in AM is demonstrated.

\section{Experimental}

Directed energy deposition was used to fabricate two $110 \mathrm{~mm}$ long x $11 \mathrm{~mm}$ wide $\mathrm{x} 70 \mathrm{~mm}$ tall walls from pre-alloyed stainless steel 304L powder as shown schematically in Figure 1 . The walls were built on a $150 \mathrm{~mm}$ x $80 \mathrm{~mm}$ x $11 \mathrm{~mm}$ annealed 304L stainless steel (ASTM A479 standard [21]) plate with deposition parameters given in Table 2. The components were fabricated in a custom built environmentally controlled deposition system. The environment was controlled by a gas purifier (MBraun Model MB 200G), and the oxygen levels were measured using an oxygen analyzer (General Electric CGA 351 Zirconium Oxide Oxygen Analyzer). The chamber was purged with ultra-high purity argon to maintain oxygen levels between 60 and 110 ppm in the chamber during processing. 
An ytterbium fiber laser (IPG Photonics ${ }^{\circledR}$ YLR-12000-L) with a wavelength ranging from 1070 to $1080 \mathrm{~nm}$ was delivered to the part through a $600 \mu \mathrm{m}$ diameter fiber inside of a copper cooled reflective optics system. The optics system consisted of a $49.5 \mathrm{~mm}$ diameter collimator with a focal length of $125 \mathrm{~mm}$ and focusing optics with a focal length of $600 \mathrm{~mm}$. The powder was delivered using a Mark XV Precision Powder Feeder (Powder Feed Dynamics) to a custom designed four-nozzle powder delivery system with powder orifices approximately $1.43 \mathrm{~mm}$ in diameter. The powder feedstock was fabricated by gas atomization in nitrogen (Carpenter Powder Products, Corp.) with a size distribution between $45 \mu \mathrm{m}$ and $145 \mu \mathrm{m}$, which corresponds to a sieve size distribution between $+325 /-100$. The elemental composition of the prealloyed 304L powder is given in Table 3. The substrate was placed at a location approximately $10 \mathrm{~mm}$ from the nozzles, which corresponds to the focus point for the powder flow. At this location, the laser beam is in a defocused position and has a measured beam diameter of approximately $4 \mathrm{~mm}$. Characterization of the beam at this location performed using a PRIMES ${ }^{\circledR}$ Focus Monitor confirmed this diameter and a Gaussian energy density distribution for the beam.

Tensile test specimens in accordance with ASTM E8 [22], with a gauge length of $21.5 \mathrm{~mm}$, gauge width of $4 \mathrm{~mm}$, and thickness of $2 \mathrm{~mm}$, were extracted from the two walls and the baseplate by wire electrical discharge machining (EDM) as shown in Figure 2. From each wall, specimens were cut in two orientations: one set such that the tensile axis of each specimen was perpendicular to the build direction, denoted as longitudinal specimens, and the second set such that the tensile axis of each specimen was parallel to the build direction, denoted as transverse specimens. For comparison, specimens were also extracted from the annealed 304L baseplate.

The internal structure, including pores or defects, of the samples was visualized using X-ray computed tomography $(\mathrm{CT})$, which is a nondestructive technique to examine the interior 
structure of bulk materials. Here, X-ray CT (General Electric phoenix v|tome|x m) was used to quantify the porosity of the samples made by AM and to visualize and quantify internal inclusions in two representative tensile specimens. Scans were performed using a $300 \mathrm{kV}$ microfocus X-ray source with a GE DXR250 flat panel detector with a $200 \mu \mathrm{m}$ pitch. Two sets of scanning parameters were used in the inspection of the specimens, depending on the desired level of resolution. For higher resolution scans with a voxel size of $25 \mu \mathrm{m}$, an accelerating voltage of $250 \mathrm{kV}$ and a tube current of $100 \mu \mathrm{A}$ were used with 800 projections per scan and a total scan time of 26 minutes. Lower resolution scans with a voxel size of $35 \mu \mathrm{m}$ allowed for higher powers to be used with the x-ray tube, and accelerating voltages between $250 \mathrm{kV}$ and 270 $\mathrm{kV}$ with corresponding tube currents of $150 \mu \mathrm{A}$ and $130 \mu \mathrm{A}$, respectively, were used. For these two cases, 600 projections per scan and a total scan time of 14 minutes were used. These voxel sizes should allow for the identification of pores $50-70 \mu \mathrm{m}$ in diameter or larger $[23,24]$. The scans were analyzed using VGStudio Max 2.2 visualization and analysis software.

To study the potential phase transformation from austenite to martensite, nondestructive magnetic permeability measurements were made using a feritescope (Fischer Feritescope FMP 30). The microstructure of as-deposited 304L contains paramagnetic austenite, ferromagnetic ferrite, and potentially ferromagnetic martensite. Thus, the magnetic permeability of the sample will indicate the presence of ferrite and martensite together [13,25-27]. While austenite has the potential to transform to martensite with plastic deformation $[11,28,29]$, the ferrite volume fraction remains constant with deformation [30]; therefore, any increase in magnetic permeability can be attributed to a phase transformation from austenite to martensite.

Uniaxial tension tests were performed on an electromechanical testing frame (Instron 4202, $10 \mathrm{kN}$ load cell) at a strain rate of $1.2 \times 10^{-3} / \mathrm{s}$. Digital image correlation (DIC), a non-contact 
method for measuring surface deformations, was used to compute surface strains using correlation software (Vic2D, Correlated Solutions). In this technique, the surface of each sample was painted white with a black speckle pattern. A digital camera (Point Grey GRAS-50S5M-C) was used to image the gauge region of the sample at $1 \mathrm{~Hz}$ during each test, with a pixel size of 90 $\mu \mathrm{m}$. The surface deformations in the gauge region of each sample were computed based on digital images using a cubic B-spline interpolation algorithm with a subset size of 21 pixels and a step size of 5 pixels, resulting in a virtual strain gauge size of 56 pixels in the Vic2D software [31]. The axial strain in the gauge section of each sample was measured using a $21 \mathrm{~mm}$ long vertical virtual extensometer in the Vic2D software.

To examine the microstructure of the samples, samples were polished using $0.05 \mu \mathrm{m}$ colloidal silica and electrolytically etched using $20 \mathrm{wt}$ \% $\mathrm{NaOH}$ in DI water at $5 \mathrm{~V}$ for $4-10 \mathrm{~s}$. The samples were observed using an optical microscope (Keyence VHX-2000) in which ferrite could be detected, as the $\mathrm{NaOH}$ solution preferentially attacks delta-ferrite rendering it dark in micrographs [32]; however, it was not possible to clearly distinguish grains with this method. Therefore, grains were observed using electron backscatter diffraction (EBSD; Oxford Nordlys Max2). For EBSD imaging, the samples were polished using $0.05 \mu \mathrm{m}$ colloidal silica, and were not etched.

Elemental analysis was performed on the deposited material and the baseplate with the results shown in Table 3 (Element Materials Technology, Newtown, PA). Nitrogen content was measured by inert gas fusion, while carbon and sulfur content were measured by combustion testing in accordance with ASTM E1019 [33], and the remaining elements were measured by optical emission spectrometry in accordance with ASTM E1086 [34]. 


\section{Results and Discussion}

\subsection{Overview}

The measured mechanical properties under uniaxial tension for all samples are given in Table 4, while representative engineering stress-strain curves of samples extracted from the two walls and annealed baseplate are shown in Figure 3. As seen by the significant standard deviations in Table 4, strength and ductility vary between samples extracted from a single wall made by AM. The samples made by AM have reduced tensile strength and elongation as compared to the annealed baseplate. With respect to processing conditions, in the same material direction, samples extracted from the low power wall exhibited higher yield and tensile strengths than samples extracted from the high power wall, while a similar, but weaker trend is seen in elongation.

For additively manufactured samples made using a single set of processing conditions, longitudinal specimens have lower elongation than transverse specimens, but there is no consistent trend in strength versus direction, which we explain in section 3.3.2. Within the same wall, the yield and tensile strengths increase in longitudinal samples as the distance between the sample and the baseplate, which was water cooled to room temperature, decreases (see Figure 4).

X-ray CT analysis was performed to visualize and quantify the volume fraction of pores and inclusions in selected samples prior to testing. No lack of fusion defects were found, but at the

resolution of the X-ray CT scanning parameters used, a distribution of small spherical pores and inclusions with high contrast were detected, and classified as internal defects. The volume fractions of defects were found to be in the range of $0.048 \%$ to $0.191 \%$ across both power levels. These rather low values verify that the mechanical responses measured here are not impacted by defects in the mechanical testing specimens. 


\subsection{Effect of processing parameters on grain size and morphology}

The microstructures of longitudinal samples extracted from the low and high power walls are shown in Figure 5, where the relative sizes of grains and layer bands within each wall is seen in Figures $5 \mathrm{a}$ and $5 \mathrm{~b}$. In the low power wall (Figure $5 \mathrm{a}$ ), no grains span the approximately $0.8 \mathrm{~mm}$ tall layer height. In the high power wall (Figure 5b), some grains span the $1.2 \mathrm{~mm}$ layer height. Figures $5 \mathrm{c}$ and $5 \mathrm{~d}$ show the presence of columnar $\delta$-ferrite dendrites inside the austenite matrix, but as shown in Figure 5c, upon magnification of the layer boundary in Figure 5b, no sharp transition in microstructural features is visible across the layer boundary. During rapid solidification of austenitic stainless steels, the transformation from $\delta$-ferrite to austenite is seldom fully complete, resulting in residual ferrite dendrites in the austenite matrix upon solidification [35].

EBSD was used to quantitatively describe the size and morphology of the grains in the two additively manufactured walls as a function of position and linear heat input. Figure 6 shows representative inverse pole figures of samples extracted $15 \mathrm{~mm}$ from the top and $7 \mathrm{~mm}$ from the bottom of each of the two walls. Comparison of these images qualitatively shows how the grain size and morphology change as a function of position within each of the two walls, as well as between the two walls. At the bottom of the walls, the microstructure contains columnar grains that appear to track the predominant heat flow path that results from the deposition of follow on layers. At the top of the walls, the microstructure is more irregular, but largely approaches an equiaxed morphology. The measured grain areas in Table 5 are largely skewed toward small grains; thus, a standard deviation is not appropriate to describe the data. These measurements of mean grain size indicate that in a single wall, grains at the top of the wall are larger than those at 
the bottom due to more rapid cooling at the bottom of the wall; the slower dissipation of heat as the distance from the baseplate increases and heat builds up in the wall allows for grain coarsening at the top of the wall [36,37]. When comparing mean grain sizes from different walls, the samples extracted from the low power wall had smaller grains than those from the high power wall at the same position (Table 5). This is due to the fact that the higher linear heat input in the high laser power wall results in a larger melt pool, and therefore a smaller thermal gradient and slower cooling with respect to the wall built with the lower linear heat input $[1,20,38]$.

To quantify the effect of processing conditions on grain size, literature on the effect of processing conditions on the solidification cooling rate in welds [39] as well as microstructures in the heat affected zone (HAZ) in welds is examined [40-44]. Relevant to the present study, researchers have developed models to describe the grain growth in the HAZ of a weld as a function of preheat temperature and linear heat input $[43,44]$. These models assume that nucleation is complete and that grain growth is controlled by diffusion, giving the growth rate of grains in the $\mathrm{HAZ}$ at a given temperature, $T$, as

$$
\frac{d g}{d t}=\frac{k_{1}}{2 g} \exp \left(-\frac{Q}{R T}\right)
$$

where $g$ is the grain size, $t$ is time, $k_{l}$ is a kinetic constant, and $Q$ is the activation energy for grain growth. After integration, the grain size is given as

$$
g^{2}=k_{1} \alpha \tau \exp \left(-\frac{Q}{R T_{P}}\right)+g_{0}^{2}
$$

where $g_{0}$ is the initial grain size, $T_{P}$ is the peak temperature, and $\alpha$ and $\tau$ are defined as

$$
\alpha=\sqrt{\frac{2 \pi R T_{P}}{Q}} \text {, and }
$$




$$
\tau=\frac{q / v}{2 \pi \lambda e} \frac{1}{\left(T_{P}-T_{0}\right)}
$$

where $q / v$ is the linear heat input, $\lambda$ is the thermal conductivity, $T_{0}$ is the preheat temperature, and $\tau$ is the time to heat from $T_{0}$ to $T_{P}$. The material properties for austenitic steels are given in Table 6.

In general, these models show that at the same starting temperature, the time at elevated temperature increases with linear heat input, resulting in the growth of larger grains, and at the same linear heat input, the time at elevated temperature increases with preheat temperature, also resulting in the growth of larger grains.

In order to apply these models to additive manufacturing, one must determine if the deposited material may be considered as a HAZ in a weld, with a given initial grain size. During the keyhole welding of $304 \mathrm{~L}$ stainless steel, increases in the linear energy input from $40 \mathrm{~J} / \mathrm{mm}$ to $100 \mathrm{~J} / \mathrm{mm}$ showed that the temperature gradient, G, cooling rate GR, which determines the scale of the solidification structure (where $R$ is the solidification rate), and $\mathrm{G} / \mathrm{R}$, which determines the solidification morphology, all approach steady state values by $100 \mathrm{~J} / \mathrm{mm}$ [39]. Therefore, as linear heat inputs of $271 \mathrm{~J} / \mathrm{mm}$ and $377 \mathrm{~J} / \mathrm{mm}$ were used in the present study, the scale and morphology of the solidified microstructure is not expected to differ significant between the conditions studied. Thus, we may assume that the initial solidified grain size is approximately constant as a function of position within these stainless steel 304L walls, as well as between the low and high linear heat input walls. We can therefore approximate the deposited material as a HAZ, and assume that the grain growth in additive manufacturing occurs due to the reheating cycles that the material is exposed to as additional layers are deposited, analogous to those seen in a HAZ of a multi-pass weld. 
We can then use this grain growth model to predict the impact of the thermal cycles between a preheat temperature and a peak temperature on the resulting grain size. As additional layers are deposited during AM, the temperature of the component, which can be compared to a weld pre-heat temperature, increases, leading to an increase in weld pool size and a reduced thermal gradient $[45,46]$. For previously deposited layers, this temperature increase with additional layers can be compared to the thermal cycles experienced by the HAZ in multi-pass welds, which are limited to solid state transformations or grain growth. Thermocouple measurements indicated that as the walls in the present study were built, the baseplate temperature increased to a steady state value of $387^{\circ} \mathrm{C}(660 \mathrm{~K})$ throughout the deposition. This steady state baseplate temperature was reached after the deposition of 5-10 layers. Therefore, we can assume that during deposition, the preheat temperature of the HAZ is approximately room temperature (298K) near the baseplate, while near the top of the build, a lower bound for the preheat temperature is taken to be $660 \mathrm{~K}$.

To apply the kinetic grain growth model shown in equations $2-4$, we calibrated the model using data from the high linear heat input wall, which results in larger grain growth than the low linear heat input wall. Assuming a preheat temperature of $298 \mathrm{~K}$ at the bottom of the wall, and $660 \mathrm{~K}$ at the top of the wall, Figure 7 shows the average grain area, $\mathrm{g}^{2}$, versus $\tau$, which gives calibrated constants of $\mathrm{g}_{0}^{2}=1219 \mu \mathrm{m}^{2}$ and $\mathrm{k}_{1}=1.9 \times 10^{9} \mu \mathrm{m}^{2} / \mathrm{s}$. These values are deemed reasonable, as the starting grain size is approximately $40 \mu \mathrm{m}$ in diameter, and the $\mathrm{k}_{1}$ value is the same order of magnitude as that found in [43].

With this calibrated grain growth model, the grain areas in the lower linear heat input wall were predicted to be $4856 \mu \mathrm{m}^{2}$ and $5813 \mu \mathrm{m}^{2}$, as shown in Figure 7, which are close to the 
experimentally measured mean grain areas shown in Table 5 . We note that the prediction of grain growth at the top of the low power wall is more accurate than that at the bottom.

This approach demonstrates that classical welding models of grain growth within the HAZ of a weld can be calibrated and used to predict the grain size within an additively manufactured component as a function of processing history. The quantitative connection between processing and structure is critical for $\mathrm{AM}$ as the local grain size within components in turn dictates the mechanical properties as described in next section.

\subsection{Effect of grain size and morphology on mechanical properties}

\subsubsection{Hall-Petch relationship}

The Hall-Petch equation describes the relationship between grain size and yield strength in equiaxed metals as $[47,48]$ :

$$
\sigma_{y}=\sigma_{0}+\frac{k}{\sqrt{d}}
$$

where $\sigma_{y}$ is the yield strength, $d$ is the average grain diameter, and $\sigma_{0}$ and $k$ are material constants.

In order to define the grain morphology in terms of a quantifiable metric, we approximate the grains in Figure 6 as elliptical and define the grain aspect ratio as the ratio of the major axis, $a$, to the minor axis, $b$, of each grain such that an aspect ratio of 1 indicates an equiaxed grain. Figure 8 is a histogram of the aspect ratios of the grains from the top and bottom of each of the two walls based on EBSD data shown in Figure 6. The average aspect ratios for the top and bottom of each wall are shown in Table 5. Comparing data for each wall independently, grains at the top 
of the wall were found to have smaller aspect ratios, meaning they are more equiaxed than grains at the bottom of each wall. Comparing data between walls, it was found that the wall made by low linear heat input resulted in more equiaxed grains than the wall made using high linear heat input.

To link the grain size to the yield strength as a function of position, orientation, and linear heat input, we use the average grain areas, aspect ratios, and yield strengths presented in Table 5. In particular, to incorporate the potential anisotropy, we define a relevant grain dimension as the length of the grain in the direction of the applied tensile stress. Approximating the orientation of the elliptical grains as that in which the major axes are aligned with the build direction, the average lengths of major and minor axes are considered to be the relevant grain dimension, $\mathrm{d}$, in the transverse, and longitudinal samples, respectively. Using the average grain areas and aspect ratios in Table 5, the average lengths of the minor and major axes can be calculated using the following equations:

$$
\begin{gathered}
A=\pi a b \\
r=b / a
\end{gathered}
$$

where $A$ is the average grain size, $r$ is the average aspect ratio of the grains at the given location and linear heat input, and $a$ and $b$ are the average lengths of the major and minor grain axes, respectively. The resulting $a$ and $b$ values are given in Table 5 .

The yield strengths for longitudinal samples extracted from the top and bottom of each wall are plotted versus $\mathrm{d}^{-0.5}$ using the minor axis of the relevant grains in Figure 9. Regarding samples tested in the transverse direction, the grain sizes and morphologies vary in these samples as a function of position; thus, the average of the major axis values from the top and bottom longitudinal samples is taken as the major axis of transverse sample made by the same laser 
power as shown in Table 5. Thus, in addition to longitudinal data in Figure 9, the average yield strengths for the transverse samples for the two walls are plotted versus $\mathrm{d}^{-0.5}$ using the corresponding grain major axis values. The data of yield strength and $\mathrm{d}$ of each point plotted in Figure 9 are explicitly given in Table 5.

A linear fit of the yield strength versus relevant grain dimension gives values of $\sigma_{0}=194$ $\mathrm{MPa}$ and $\mathrm{k}=695 \mathrm{MPa} \sqrt{\mu m}$ to describe the Hall-Petch relationship between yield strength and grain size. The values of $\sigma_{0}$ and $\mathrm{k}$ are in line with data of stainless steels [49]. While there are some discrepancies in the predicted yield strength versus $\mathrm{d}^{-0.5}$, in that not all data lies on the line, likely due to the spread in grain size at a given position in these additively manufactured walls, the general trend of increasing yield strength with decreasing grain size is demonstrated.

In summary, in the same orientation, specimens from the low power wall have higher yield and tensile strengths than those in the high power wall due to grain boundary strengthening due to smaller grains. In a single wall, the grain size increases with increasing distance from the baseplate, resulting in a decrease in yield and tensile strengths with increasing distance from the baseplate as shown in Figure 4. The link between relevant grain dimension and yield strength is described by a Hall-Petch relationship.

\subsubsection{Anisotropy}

Due to large directional thermal gradients produced by its characteristic layer-by-layer build paths, the microstructures of components made by AM are anisotropic, which generally results in anisotropic mechanical properties. In austenitic stainless steels deposited by AM, microstructural grains and ferrite dendrites are preferentially orientated along the highest thermal gradient [20]; however, due to the rapid solidification and subsequent remelting of material with 
the additional material layers, these dendrites are oriented chaotically within the components made by AM (see Figure 5c).

When a sample with long and narrow columnar grains orientated along the build direction is plastically deformed under uniaxial tension in the same direction, dislocations are required to cross fewer grain boundaries to elongate the sample, which results in lower yield and tensile strengths than in samples deformed along the longitudinal direction. This anisotropy in microstructure and mechanical properties is evident in other material systems produced by DED or PBF, such as Ti-6Al-4V, in which large columnar grains extend across numerous build layers [50-52]; however, the grains in the present study are confined to individual build layers, as shown in Figures 5a and 5b.

In the low power wall, grains have small aspect ratios and grow within single layers. In the high power wall, grains are elongated with slightly higher aspect ratios, but virtually no grains extend across multiple layers. However, the presence or absence of anisotropy cannot be addressed directly in the present study due to the convolution of both direction and location in the tested samples. As shown in Figure 4, the yield and ultimate tensile strengths in longitudinal samples vary with position, while the average yield and ultimate tensile strengths in the transverse samples fall within the ranges of the corresponding longitudinal data. Since the gauge regions of the transverse samples span the gauge regions of approximately the three central longitudinal samples as shown in Figure 2, the effects of direction and location cannot be separated in the transverse samples. Thus, due to this convolution of data from different directions and locations, the possible macroscopic anisotropy of mechanical properties in the walls made by AM cannot be determined. 


\subsection{Phase Transformation}

The superior mechanical properties of the baseplate compared to the material made by AM are attributed to the deformation-induced martensitic transformation that occurs in the annealed 304L, which results in significant strain hardening and high ductility $[11,17,53]$. The transformation from austenite to martensite in the annealed baseplate material, and absence of this phase transformation in the additively manufactured material, was confirmed with magnetic permeability measurements and optical microscopy, and explained by elemental analysis.

The magnetic permeability of the tensile samples was measured in the gauge region before testing and after plastic deformation of the gauge regions of each sample. An increase in magnetic permeability with plastic strain in the baseplate material confirms the phase transformation, while no significant change in magnetic permeability with plastic strain in the additively manufactured material indicates a lack of phase transformation in this material. Here, we report the ferrite number $(\mathrm{FN})$, which is a measure of magnetic permeability of the sample, and which is the standard unit of measurement for reporting ferromagnetic content in welded austenitic stainless steels $[54,55]$.

The initial magnetic permeability readings in baseplate samples and those made by additive manufacturing were found to be 1-3 FN in all cases. The increase in FN from the initial measurements to the final measurement of FN in the plastically deformed gauge section of each sample is given in Table 4. The resolution of FN measurements with the feritescope is on the order of 1-2 FN. Therefore, in samples extracted from the walls made by AM, the change in FN after plastic deformation, on the order of $1 \mathrm{FN}$, is not significant, indicating little to no phase transformation with plastic deformation in these samples. However, the change in magnetic 
permeability measurement of $41.7 \mathrm{FN}$ is significant in samples extracted from the annealed baseplate, which is indicative of significant phase transformation from austenite to martensite in the annealed material.

Deformation-induced phase transformation occurs in austenitic stainless steels within a certain temperature range, denoted as $\mathrm{M}_{\mathrm{s}}{ }^{\sigma}$ to $\mathrm{M}_{\mathrm{d}}$, which depends on the alloy's chemical composition. When deformed above the martensite finish temperature, $M_{d}$, the austenite is stable, and undergoes plastic deformation with no subsequent phase transformation to martensite. Between $\mathrm{M}_{\mathrm{s}}{ }^{\sigma}$ and $\mathrm{M}_{\mathrm{d}}$, the austenite plastically deforms upon deformation, and the intersections of dislocations and slip bands provide nucleation sites for the austenite to transform to martensite $[11,12,56]$. Since $M_{d}$ is difficult to obtain from experiments, Angel [9] described an $M_{d 30}$ temperature as the temperature at which 50 vol. $\%$ of the austenite transforms to martensite with an applied true strain of $30 \%$, which is given by the following empirical expression:

$$
M_{d 30}\left({ }^{\circ} C\right)=413-462(C+N)-9.2 S i-8.1 M n-13.7 C r-9.5 N i-18.5 M o,
$$

where all elements are in weight percentage (wt. \%). The $\mathrm{M}_{\mathrm{d} 30}$ temperature serves as a pseudo-upper bound for martensitic phase transformation.

The absence or occurrence of martensitic phase transformation can be verified by computing $M_{d 30}$. If the $M_{d 30}$ temperature of the annealed baseplate or material made by AM is below room temperature, at which all the tests in this study were performed, it is unlikely that phase transformation will occur in the specimens with plastic deformation. Based on the chemical analysis results in Table 3 and Eqn. 8, $\mathrm{M}_{\mathrm{d} 30}$ in the builds made by $\mathrm{AM}$ and the annealed baseplate were calculated to be $-3.6^{\circ} \mathrm{C}$ and $43.3^{\circ} \mathrm{C}$, respectively. The low $\mathrm{M}_{\mathrm{d} 30}$ temperature in the deposited wall is due to the fact that the SS304L powder was manufactured by gas atomization in nitrogen, which is an austenite stabilizer. Gas atomization of the powder in nitrogen resulted in a 
higher nitrogen content in the powder and walls compared to the baseplate. This explains the experimental observation of phase transformation in the baseplate, in which the austenite phase was metastable, and the absence of transformation in the additively manufactured material, in which the austenite phase was stable.

The absence of a phase transformation in the 304L deposited by AM is significant as it resulted in a lower ultimate tensile strength than the annealed 304L plate, in which the microstructural phase transformation provided a high rate of macroscopic strain hardening.

\section{Summary and Conclusions}

Two 304L stainless steel walls were fabricated using laser-based directed energy deposition additive manufacturing in order to elucidate the effect of processing parameters, namely linear heat input, on the anisotropic and heterogeneous tensile mechanical properties within a component. The primary conclusions from this study are:

- Slightly elongated grains grew along the build direction in the material made by AM, resulting in anisotropic elongation in which longitudinal specimens had lower elongations than transverse specimens. However, no clear anisotropy in macroscopic yield or tensile strength was identified in the present study.

- An existing kinetic grain growth model, originally formulated to describe the grain growth in the HAZ of welds, was calibrated to predict the effect of linear heat input and location within an additively manufactured component on grain size. This provides a quantitative connection between processing parameters and microstructure for AM components. 
- The location-dependent yield strength was found to follow a Hall-Petch dependence on location- and direction-dependent grain size, demonstrating a quantitative connection between heterogeneous, anisotropic microstructure and mechanical properties in AM.

- The wall fabricated using lower linear heat input had a finer microstructure, and therefore, higher yield and tensile strengths, than the wall fabricated with the higher linear heat input. The coarser microstructure at the top of the walls compared to the bottom of the walls was predicted to be due to a decreased cooling rate with increased distance from the substrate, which results in a lower yield and tensile strengths. The trend in grain size as a function of linear heat input and position corresponded to the predictions of the kinetic grain growth model. In addition, the yield strength as a function of grain size and morphology followed a Hall-Petch relationship.

- The ultimate tensile strength and elongation of samples extracted from the 304L stainless steel walls made by DED AM were found to be lower than those in the annealed baseplate. This is due to the fact that strain-induced martensitic transformation, which provides high strain hardening and facilitates significant ductility, occurred in the annealed 304L plate, but not the $304 \mathrm{~L}$ made by AM as the higher nitrogen content in the pre-alloyed powder stabilized the austenite phase in the deposited walls.

\section{Acknowledgements}

The financial support provided by the National Science Foundation through award number CMMI-1402978 is gratefully acknowledged. Any opinions, findings, and conclusions or recommendations expressed in this material are those of the authors and do not necessarily 
reflect the views of the National Science Foundation. We acknowledge Mr. Jay Tressler for the fabrication of the walls and Mr. Griffin Jones for performing the X-ray CT scans. 


\section{References}

[1] D. D. Gu, W. Meiners, K. Wissenbach, and R. Poprawe, "Laser additive manufacturing of metallic components: materials, processes and mechanisms," Int. Mater. Rev., vol. 57, no. 3, pp. 133-164, May 2012.

[2] J. Yu, M. Rombouts, and G. Maes, "Cracking behavior and mechanical properties of austenitic stainless steel parts produced by laser metal deposition," Mater. Des., vol. 45, pp. 228-235, Mar. 2013.

[3] S. Das, J. J. Beama, M. Wohlert, and D. L. Bourell, "Direct laser freeform fabrication of high performance metal components," Rapid Prototyp. J., vol. 4, no. 3, pp. 112-117, 1998.

[4] A. Mertens and S. Reginster, "Mechanical properties of alloy Ti-6Al-4V and of stainless steel 316L processed by selective laser melting: influence of out-of-equilibrium microstructures," Powder Metall., vol. 57, no. 3, pp. 184-189, 2014.

[5] A. Mertens, S. Reginster, Q. Contrepois, T. Dormal, O. Lemaire, and J. Lecomte-Beckers, "Microstructures and Mechanical Properties of Stainless Steel AISI 316L Processed by Selective Laser Melting,” Mater. Sci. Forum, vol. 783-786, pp. 898-903, May 2014.

[6] K. Guan, Z. Wang, M. Gao, X. Li, and X. Zeng, "Effects of processing parameters on tensile properties of selective laser melted 304 stainless steel," Mater. Des., vol. 50, pp. 581-586, Sep. 2013.

[7] M. F. McGuire, Stainless Steels for Design Engineers. Materials Park: ASM International, 2008.

[8] Lecroise.F and A. Pineau, "Martensitic Transformations Induced By Plastic-Deformation in Fe-Ni-Cr-C System," Metall. Trans., vol. 3, pp. 387-396, 1972.

[9] T. Angel, "Formation of Martensite in Austenitic Stainless Steels, effect of deformation, temperature and composition," J. Iron Steel Inst., pp. 165-174, 1954.

[10] G. B. Olson and M. Cohen, "Kinetics of Strain-Induced Martensitic Nucleation," Metall. Trans. A, vol. 6A, pp. 791-795, 1975. 
[11] R. G. Stringfellow, D. M. Parks, and G. B. Olson, “A constitutive model for transformation plasticity accompanying strain-induced martensitic transformations in metastable austenitic steels," Acta Metall. Mater., vol. 40, no. 7, pp. 1703-1716, 1992.

[12] G. B. Olson and M. Cohen, "A mechanism for the strain-induced nucleation of martensitic transformations,” J. Less-Common Met., vol. 28, pp. 107-118, 1972.

[13] J. Talonen, P. Aspegren, and H. Hänninen, "Comparison of different methods for measuring strain induced $\alpha$-martensite content in austenitic steels," Mater. Sci. Technol., vol. 20, no. 12, pp. 1506-1512, 2004.

[14] A. M. Beese and D. Mohr, "Effect of stress triaxiality and Lode angle on the kinetics of strain-induced austenite-to-martensite transformation," Acta Mater., vol. 59, pp. 25892600, Apr. 2011.

[15] J. B. Leblond, "Mathematical modelling of transformation plasticity in steels II: Coupling with strain hardening phenomena," International Journal of Plasticity, vol. 5, no. 6. pp. 573-591, 1989.

[16] R. G. Stringfellow and D. M. Parks, "A self-consistent model of isotropic viscoplastic behavior in multiphase materials," Int. J. Plast., vol. 7, no. 6, pp. 529-547, 1991.

[17] A. M. Beese and D. Mohr, "Anisotropic plasticity model coupled with Lode angle dependent strain-induced transformation kinetics law," J. Mech. Phys. Solids, vol. 60, pp. 1922-1940, Nov. 2012.

[18] M. L. Griffith, D. M. Keicher, C. L. Atwood, J. A. Romero, E. Smugeresky, L. D. Harwell, and D. L. Greene, "Free Form Fabrication of Metallic Components Using Laser Engineered Net Shaping (LENS),” Proc. Solid Free. Fabr. Symp., pp. 125-132, 1996.

[19] M. L. Griffith, M. T. Ensz, J. D. Puskar, C. V Robino, J. A. Brooks, J. A. Philliber, E. Smugeresky, and W. H. Hofmeister, "Understanding the Microstructure and Properties of Components Fabricated by laser Engineered Net Shaping (LENS)," Mater. Res. Soc., vol. $625,2000$.

[20] K. Zhang, S. Wang, W. Liu, and X. Shang, "Characterization of stainless steel parts by Laser Metal Deposition Shaping,” Mater. Des., vol. 55, pp. 104-119, Mar. 2014.

[21] "ASTM A479/A479M: Standard Specification for Stainless Steel Bars and Shapes for Use 
in Boilers and Other Pressure Vessels," in ASTM International, West Conshohocken, PA, 2015, pp. 1-8.

[22] "ASTM Standard E8/E8M-15a: Standard Test Methods for Tension Test of Metallic Materials," in ASTM International, West Conshohocken, PA, 2015.

[23] G. Ziółkowski, E. Chlebus, P. Szymczyk, and J. Kurzac, "Application of X-ray CT method for discontinuity and porosity detection in 316L stainless steel parts produced with SLM technology," Arch. Civ. Mech. Eng., pp. 1-7, 2014.

[24] J. A. Slotwinski, E. J. Garboczi, and K. M. Hebenstreit, "Porosity Measurements and Analysis for Metal Additive Manufacturing Process Control," J. Res. Natl. Inst. Stand. Technol., vol. 119, p. 494, 2014.

[25] W. Staib and D. I. H. Kunzel, "In-situ Ferrite Content Measurement of Duplex Steel Structures in the Chemical Industry. Practical Applications of the Alternating Field, Magnetoinductive Method," Nondestruct. Charact. Mater., pp. 614-621, 1989.

[26] A. M. Beese and D. Mohr, "Identification of the Direction-Dependency of the Martensitic Transformation in Stainless Steel Using In Situ Magnetic Permeability Measurements," Exp. Mech., vol. 51, pp. 667-676, Jul. 2011.

[27] M. Shimotomai, K. Maruta, K. Mine, and M. Matsui, "Formation of aligned two-phase microstructures by applying a magnetic field during the austenite to ferrite transformation in steels," Acta Mater., vol. 51, no. 10, pp. 2921-2932, Jun. 2003.

[28] T. LeBrun, T. Nakamoto, K. Horikawa, and H. Kobayashi, "Effect of Retained Austenite on Subsequent Thermal Processing and Resultant Mechanical Properties of Selective Laser Melted 17-4 PH Stainless Steel,” Mater. Des., 2015.

[29] S. S. M. Tavares, D. Gunderov, V. Stolyarov, and J. M. Neto, "Phase transformation induced by severe plastic deformation in the AISI 304L stainless steel," Mater. Sci. Eng. A, vol. 358, no. 1-2, pp. 32-36, 2003.

[30] R. D. K. Misra, B. R. Kumar, M. Somani, and P. Karjalainen, "Deformation processes during tensile straining of ultrafine/nanograined structures formed by reversion in metastable austenitic steels," Scr. Mater., vol. 59, no. 1, pp. 79-82, 2008.

[31] P. Reu, "Virtual Strain Gage Size Study," Exp. Tech., vol. 39, pp. 1-3, 2015. 
[32] J. R. Davis, ASM Specialty Handbook-Stainless Steels. 1994.

[33] "ASTM E1019: Standard Test Methods for Determination of Carbon, Sulfur, Nitrogen, and Oxygen in Steel and in Iron, Nickel, and Cobalt Alloys by Various Combusition and Fusion Techniques," in ASTM International, West Conshohocken, PA, 2015, pp. 1-28.

[34] "ASTM E1086: Standard Test Method for Analysis of austenitic Stainless Steel by Spark Atomic Emission Spectrometry," in ASTM International, West Conshohocken, PA, 2015, pp. 1-5.

[35] J. W. Elmer, S. M. Allen, and T. W. Eagar, "Microstructural Development during Solidification of Stainless Steel Alloys," Metall. Trans. A, vol. 20A, no. 2117-2131, 1989.

[36] X. Wu, "A review of laser fabrication of metallic engineering components and of materials," Mater. Sci. Technol., vol. 23, no. 6, pp. 631-640, Jun. 2007.

[37] W. J. Sames, K. A. Unocic, R. R. Dehoff, T. Lolla, and S. S. Babu, "Thermal effects on microstructural heterogeneity of Inconel 718 materials fabricated by electron beam melting," J. Mater. Res., vol. 29, no. 17, pp. 1920-1930, 2014.

[38] M. Ma, Z. Wang, D. Wang, and X. Zeng, "Control of shape and performance for direct laser fabrication of precision large-scale metal parts with 316L Stainless Steel," Opt. Laser Technol., vol. 45, pp. 209-216, Feb. 2013.

[39] R. Rai, J. W. Elmer, T. a Palmer, and T. DebRoy, "Heat transfer and fluid flow during keyhole mode laser welding of tantalum, Ti-6Al-4V, 304L stainless steel and vanadium," J. Phys. D. Appl. Phys., vol. 40, pp. 5753-5766, 2007.

[40] M. F. Ashby and K. E. Easterling, "The transformation hardening of steel surfaces by laser beams-I. Hypo-eutectoid steels," Acta Metall., vol. 32, no. Il, pp. 1935-1948, 1984.

[41] L. W.B., K. E. Easterling, and M. F. Ashby, "Laser Transformation Hardening of Steel II. Hypereutectoid Steels," Acta Metall., vol. 34, no. 8, pp. 1533-1543, 1986.

[42] J. C. Ion, H. R. Shercliff, and M. F. Ashby, "Diagrams for laser materials processing," Acta Metall., vol. 40, no. 7, pp. 1539-1551, 1992. 
[43] M. F. Ashby and K. E. Easterling, "A first report on diagrams for grain growth in welds," Acta Metall., vol. 30, pp. 1969-1978, 1982.

[44] J. C. Ion, K. E. Easterling, and M. F. Ashby, "A second report on diagrams of microstructure and hardness for heat-affected zones in welds," Acta Metall., vol. 32, no. 11, pp. 1949-1962, 1984.

[45] E. R. Denlinger, J. C. Heigel, P. Michaleris, and T. a. Palmer, "Effect of Inter-Layer Dwell Time on Distortion and Residual Stress in Additive Manufacturing of Titanium and Nickel Alloys," J. Mater. Process. Technol., vol. 215, pp. 123-131, 2015.

[46] V. Manvatkar, A. De, and T. DebRoy, "Spatial variation of melt pool geometry, peak temperature and solidification parameters during laser assisted additive manufacturing process," Mater. Sci. Technol., vol. 31, no. 8, pp. 924-930, 2015.

[47] E. O. Hall, “The Deformation and Ageing of Mild Steel: III Discussion of Results," Proc. Phys. Soc. Sect. B, vol. 64, pp. 747-753, 1951.

[48] N. J. Petch, “The cleavage strength of polycrystals," J. Iron Steel Inst., vol. 173, pp. 2527, 1953.

[49] K. K. Singh, S. Sangal, and G. S. Murty, "Hall-Petch behaviour of 316L austenitic stainless steel at room temperature," Mater. Sci. Technol., vol. 18, pp. 165-172, 2002.

[50] B. E. Carroll, T. a. Palmer, and A. M. Beese, "Anisotropic tensile behavior of Ti-6Al-4V components fabricated with directed energy deposition additive manufacturing," Acta Mater., vol. 87, pp. 309-320, 2015.

[51] H. Khalid Rafi, N. V Karthik, T. L. Starr, and B. E. Stucker, "Mechanical property evaluation of Ti-6Al-4V parts made using Electron Beam Melting," Solid Free. Fabr. Proc., pp. 526-535, 2012.

[52] A. M. Beese and B. E. Carroll, "Review of Mechanical Properties of Ti-6Al-4V Made by Laser- Based Additive Manufacturing Using Powder Feedstock," JOM, 2015.

[53] J. B. Leblond, G. Mottet, and J. C. Devaux, "A theoretical and numerical approach to the plastic behaviour of steels during phase transformations-I. Derivation of general relations," J. Mech. Phys. Solids, vol. 34, no. 4, pp. 395-409, 1986. 
[54] "Welding — Determination of Ferrite Number (FN) in austenitic and duplex ferriticaustenitic $\mathrm{Cr}-\mathrm{Ni}$ stainless steel weld metals." [Online]. Available:

https://www.iso.org/obp/ui/\#iso:std:iso:8249:ed-2:v1:en. [Accessed: 01-Jan-2015].

[55] P. K. Palani and N. Murugan, "Prediction of Delta Ferrite Content and Effect of Welding Process Parameters in Claddings by FCAW," Mater. Manuf. Process., vol. 21, no. 5, pp. 431-438, 2006.

[56] P. L. Mangonon and G. Thomas, "Structure and properties of thermal-mechanically treated 304 stainless steel," Metall. Trans., vol. 1, no. 6, pp. 1587-1594, 1970.

[57] Y. Xue, A. Pascu, M. F. Horstemeyer, L. Wang, and P. T. Wang, "Microporosity effects on cyclic plasticity and fatigue of LENS ${ }^{\mathrm{TM}}$-processed steel," Acta Mater., vol. 58, pp. 4029-4038, Jun. 2010.

[58] M. S. F. de Lima and S. Sankaré, "Microstructure and mechanical behavior of laser additive manufactured AISI 316 stainless steel stringers," Mater. Des., vol. 55, pp. 526532, Mar. 2014.

[59] I. Tolosa, F. Garciandía, F. Zubiri, F. Zapirain, and A. Esnaola, "Study of mechanical properties of AISI 316 stainless steel processed by 'selective laser melting', following different manufacturing strategies," Int. J. Adv. Manuf. Technol., vol. 51, pp. 639-647, Apr. 2010.

[60] V. Manvatkar, A. De, and T. Debroy, "Heat transfer and material flow during laser assisted multi-layer additive manufacturing," J. Appl. Phys., vol. 116, no. 12, 2014.

[61] S. A. David, T. DebRoy, J. C. Lippold, H. B. Smartt, and J. M. Vitek, Eds., "Trends in Welding Research: Proceedings of the 7th International Conference," 2005, p. 996. 

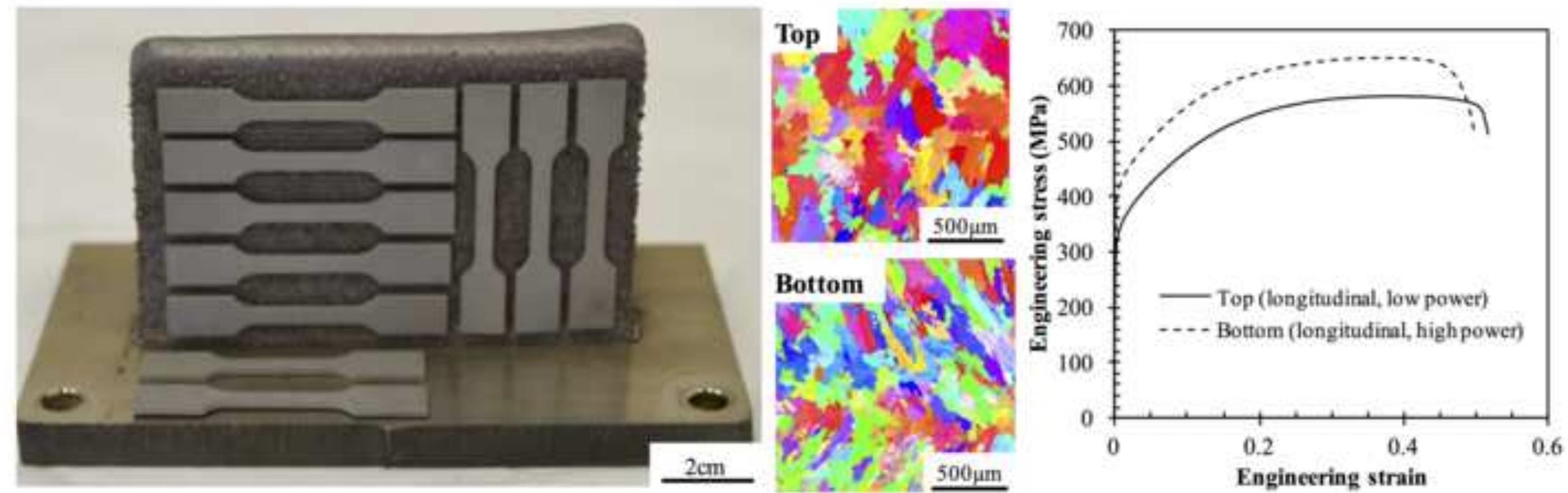


\section{Figures}

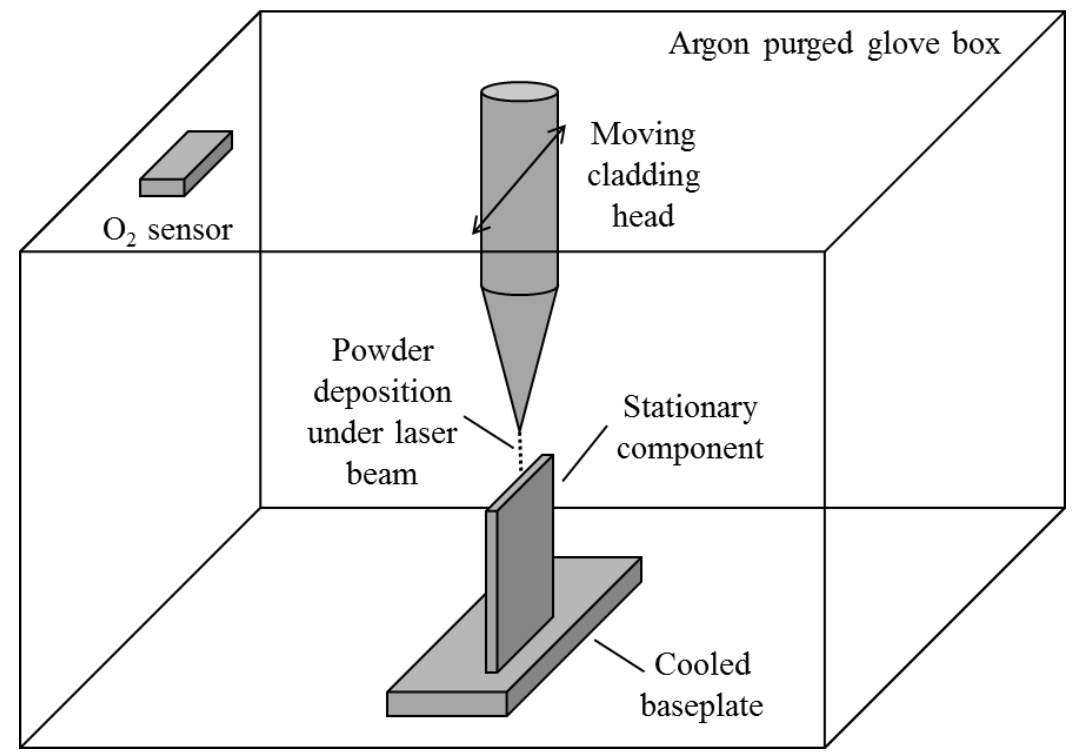

Figure 1. Schematic of the directed energy deposition process. 


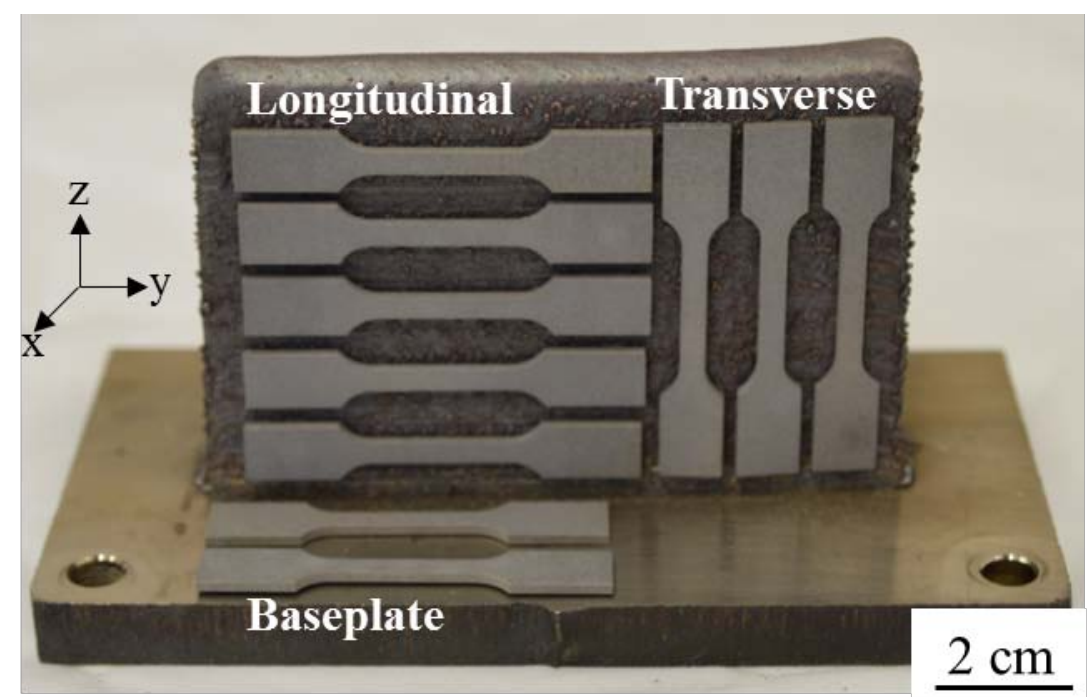

Figure 2. Photograph showing the positions from which tensile specimens were extracted in each wall. $\mathrm{X}$ is the thickness direction, $\mathrm{y}$ is the longitudinal direction, and $\mathrm{z}$ is the build, or transverse, direction. 


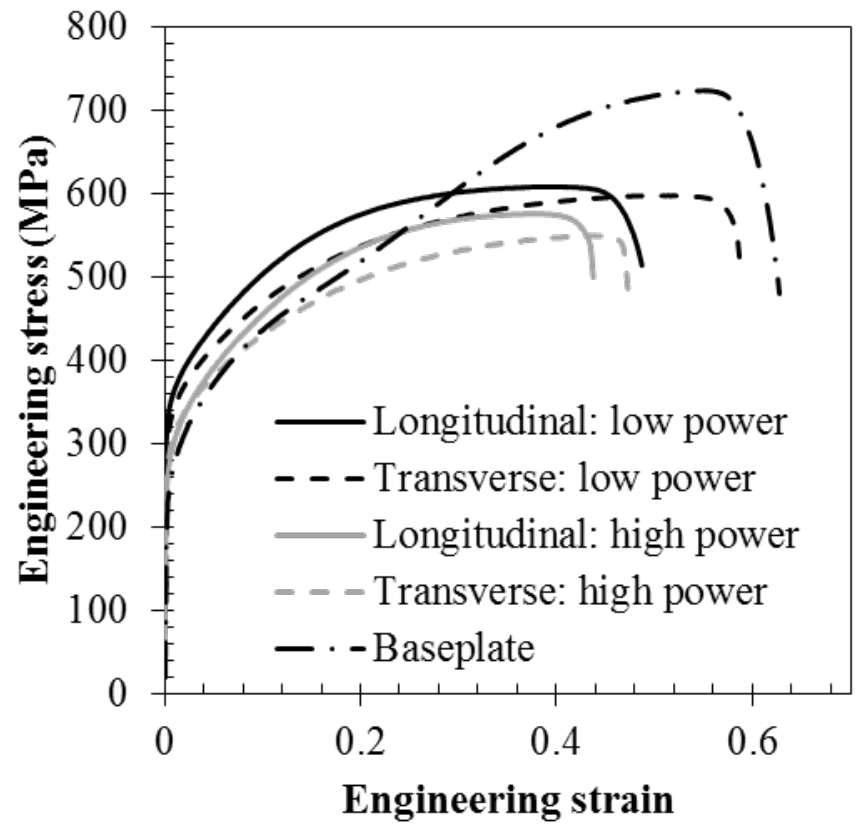

Figure 3. Representative engineering stress-strain curves of uniaxial tension samples extracted from the low power $(2.3 \mathrm{~kW})$ wall and high power $(4 \mathrm{~kW})$ wall in two directions, as well as a sample from the annealed baseplate. 
(a)

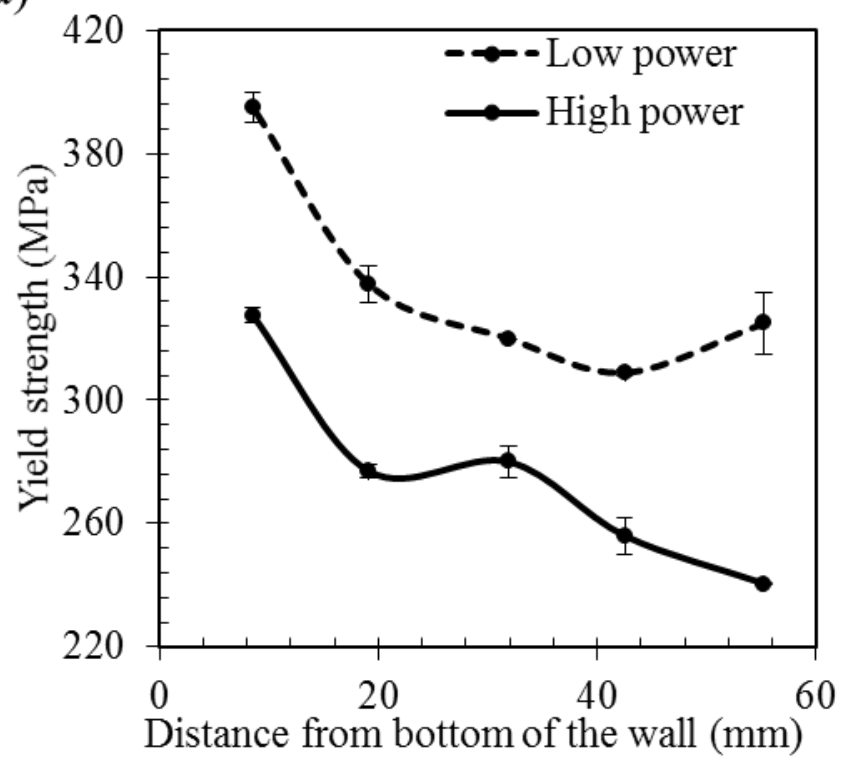

(b)

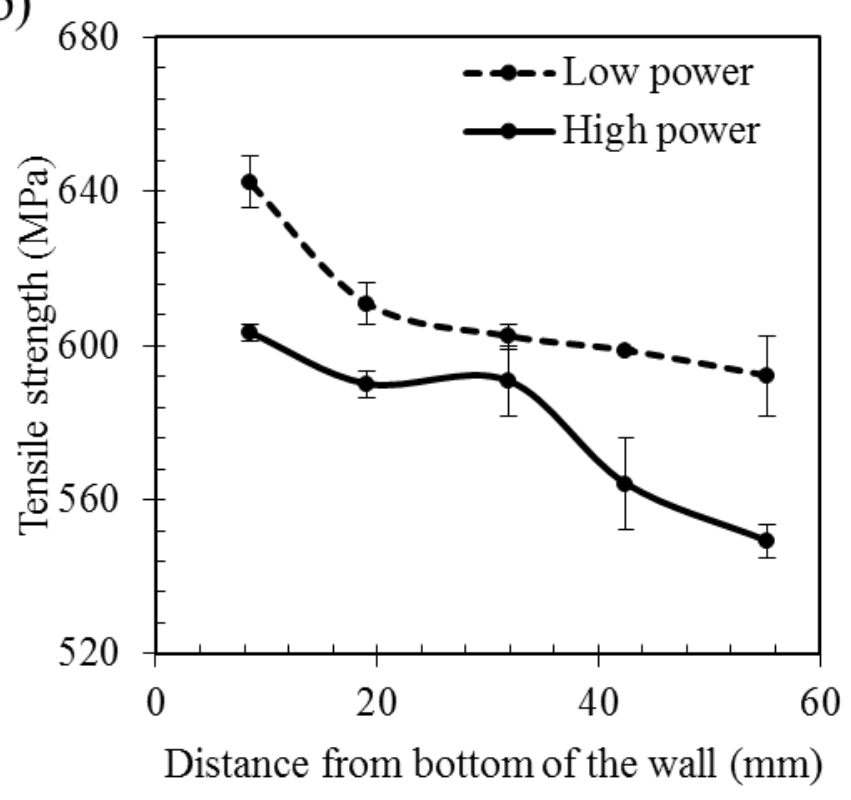

Figure 4. Yield (a) and ultimate tensile strength (b) in longitudinal samples as a function of the distance of the sample gauge region from the baseplate. 


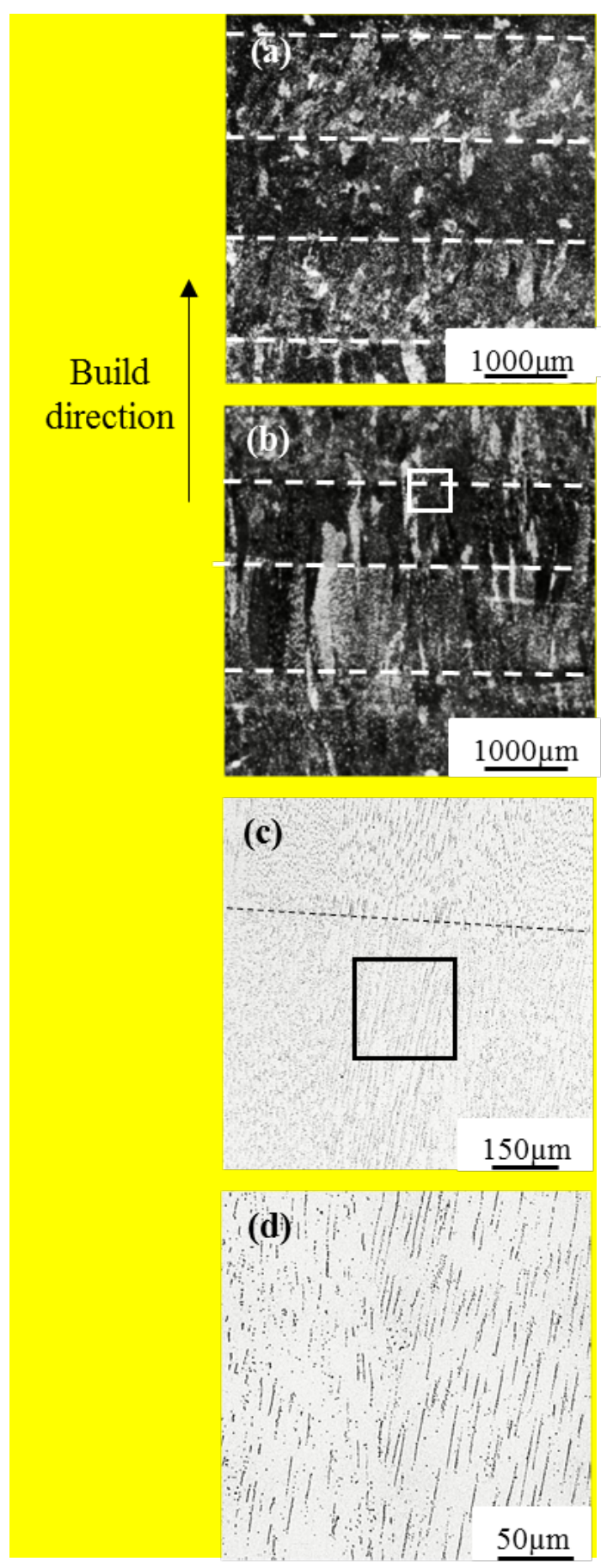

Figure 5. Optical micrographs of broken longitudinal samples in which the build direction is vertical and subsequent build layers are horizontal in the images. Dashed lines indicate the transition between subsequent build layers. (a) Image of a sample extracted from the low power wall showing short grains within single layers. (b) Image of a sample extracted from the high 
power wall showing slightly elongated grains extending the full layers. (c) Zoom in of inset in (b) showing the lack of a sharp transition in microstructural features between subsequent build layers in which the bright phase is austenite and the dark features are skeletal $\delta$-ferrite dendrites.

(d) Zoom in of inset in (c) showing $\delta$-ferrite dendrites in the austenite matrix. 

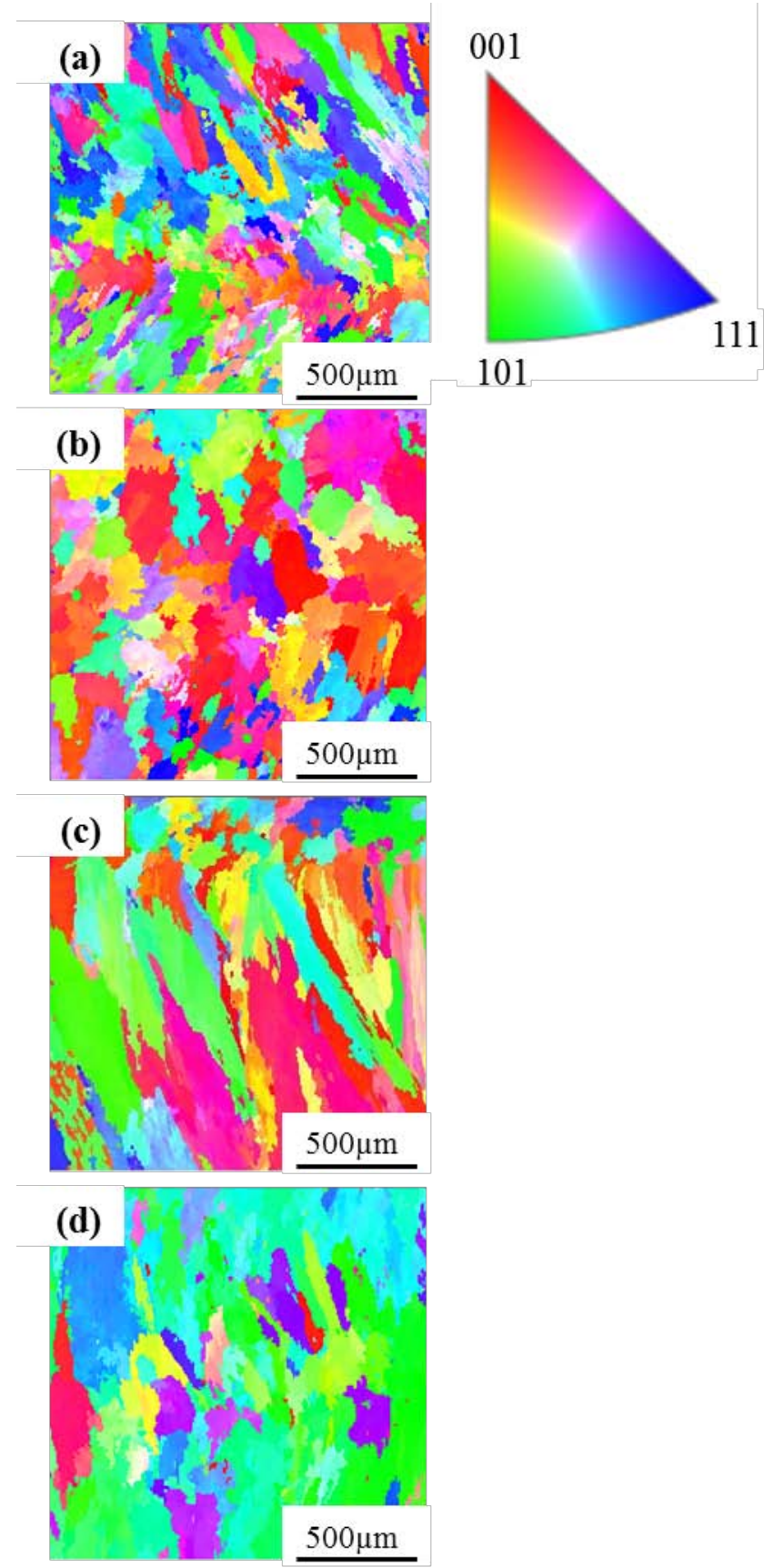

Figure 6. EBSD inverse pole maps of the $y-z$ plane in longitudinal samples. Images of samples (a) $7 \mathrm{~mm}$ from the bottom of the low power wall, (b) $15 \mathrm{~mm}$ from the top of the low power wall, (c) $7 \mathrm{~mm}$ from the bottom of the high power wall and (d) $15 \mathrm{~mm}$ from the top of the high power wall. 


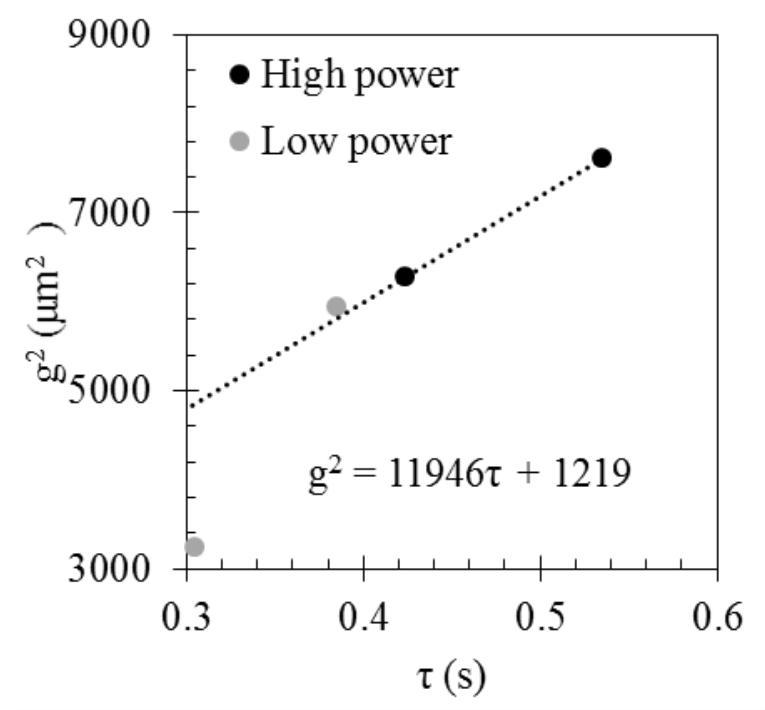

Figure 7. Average grain area versus time to heat for samples extracted $7 \mathrm{~mm}$ from the bottom and $15 \mathrm{~mm}$ from the top of both the low power wall and the high power wall, where average grain size was extracted from EBSD data shown in Figure 6 and detailed in Table 5. Data from the high power wall (black symbols) were used to fit the kinetic grain growth model, while data from the low power wall are shown in gray. The fitted line was used to calibrate the kinetic grain growth model to find the initial grain size, $g_{0}$, and the kinetic constant, $k_{l}$. This calibrated model was used to predict grain growth as a function of processing parameters for the low power wall. 


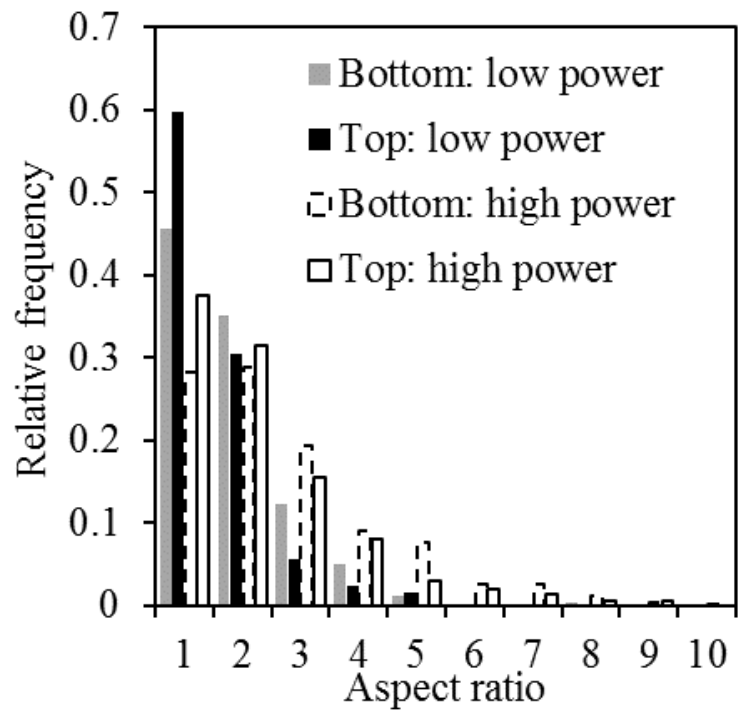

Figure 8. Histogram of grain aspect ratios for samples extracted $7 \mathrm{~mm}$ from the bottom, and 15 $\mathrm{mm}$ from the top, of both low power and high power walls. Data was extracted from EBSD maps, including those shown in Figure 6. 


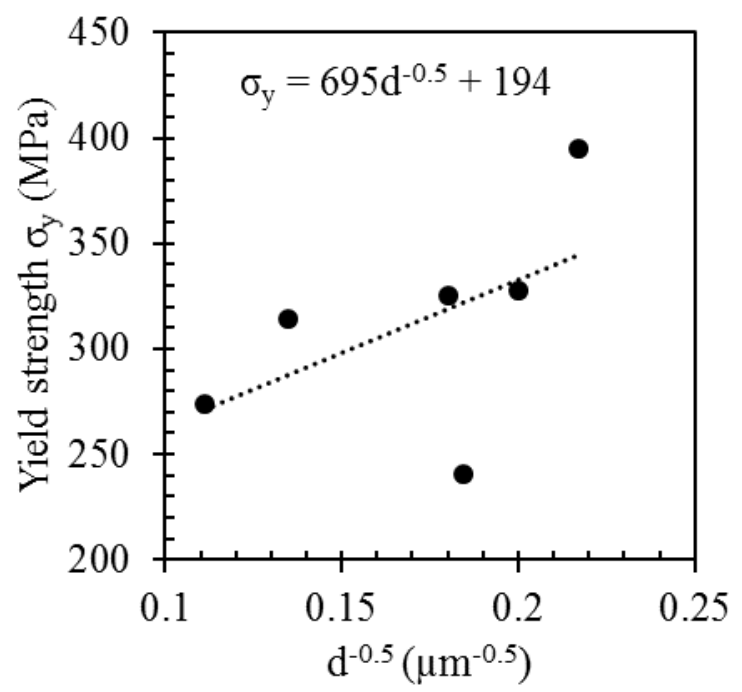

Figure 9. Yield strength versus $\mathrm{d}^{-0.5}$, where $\mathrm{d}$ is the relevant grain diameter in the direction of applied tensile load. The fitted line was used to determine the Hall-Petch parameters, $\sigma_{0}$ and $k$. 


\section{Tables}

Table 1. Summary of mechanical properties of AISI 304, 316 and 316L stainless steel fabricated by additive manufacturing compared with wrought properties reported in the literature.

\begin{tabular}{|c|c|c|c|c|c|c|c|c|c|}
\hline & $\begin{array}{c}\text { Stainless } \\
\text { steel } \\
\text { alloy } \\
\end{array}$ & $\begin{array}{c}\text { Laser } \\
\text { power }(W)\end{array}$ & $\begin{array}{c}\text { Scanning } \\
\text { speed }(\mathrm{mm} / \mathrm{s})\end{array}$ & $\begin{array}{l}\text { Linear heat } \\
\text { input }(\mathbf{J} / \mathbf{m m})\end{array}$ & Density & Orientation & $\begin{array}{c}\text { Yield strength } \\
\text { (MPa) }\end{array}$ & $\begin{array}{c}\text { Tensile } \\
\text { strength } \\
\text { (MPa) }\end{array}$ & $\begin{array}{c}\text { Elongation } \\
(\%)\end{array}$ \\
\hline \multicolumn{10}{|c|}{ Directed energy deposition } \\
\hline \multirow{2}{*}{$\begin{array}{c}\text { Griffith et al., } 2000 \\
\text { [19] }\end{array}$} & \multirow{2}{*}{304} & \multirow[b]{2}{*}{-} & \multirow[b]{2}{*}{-} & \multirow[b]{2}{*}{-} & \multirow{2}{*}{$100 \%$} & Longitudinal & 448 & 710 & 59 \\
\hline & & & & & & Transverse & 324 & 655 & 70 \\
\hline \multirow{2}{*}{$\begin{array}{l}\text { Griffith et al., 1996, } \\
2000[18,19]\end{array}$} & \multirow{2}{*}{316} & \multirow{2}{*}{-} & \multirow{2}{*}{-} & \multirow{2}{*}{-} & \multirow{2}{*}{$100 \%$} & Longitudinal & 593 & 807 & 30 \\
\hline & & & & & & Transverse & 448 & 793 & 66 \\
\hline Xue et al., 2010 [57] & 316 & - & - & - & $93.2-97.4 \%$ & Longitudinal & $363-487$ & $648-970$ & $20-44$ \\
\hline \multirow{2}{*}{$\begin{array}{c}\text { Zhang et al., } 2013 \\
{[20]}\end{array}$} & \multirow{2}{*}{316} & \multirow{2}{*}{$600-1400$} & \multirow{2}{*}{$2-10$} & \multirow{2}{*}{$75-500$} & \multirow[t]{2}{*}{ 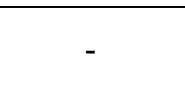 } & Longitudinal & 558 & 639 & 21 \\
\hline & & & & & & Transverse & 352 & 536 & 46 \\
\hline $\begin{array}{l}\text { Milto et al., } 2013 \\
\text { [58] }\end{array}$ & 316 & $200-350$ & $3-8$ & $24-60$ & $91 \%$ & Transverse & $207-261$ & $414-539$ & $38-45$ \\
\hline \multirow{2}{*}{ Yu et al, 2012 [2] } & \multirow{2}{*}{$316 \mathrm{~L}$} & \multirow{2}{*}{$570 / 750$} & \multirow{2}{*}{$13 / 17$} & \multirow{2}{*}{45} & \multirow{2}{*}{$99.6 \%$} & Longitudinal & 490 & 685 & 51 \\
\hline & & & & & & Transverse & 280 & 580 & 62 \\
\hline Ma et al., 2013 [38] & $316 \mathrm{~L}$ & $600-1650$ & $7-23$ & $69-90$ & $96.5-97.5 \%$ & - & $400-440$ & $430-510$ & $14-20$ \\
\hline \multicolumn{10}{|l|}{ Wrought } \\
\hline Guan et al., 2013 [6] & 304 & & & & & & $\geq 205$ & $\geq 520$ & $\geq 40$ \\
\hline $\begin{array}{c}\text { Tolosa et al., } 2010 \\
{[59]}\end{array}$ & 316 & & & & & & $220-270$ & $520-680$ & $40-45$ \\
\hline
\end{tabular}


Table 2. Processing parameters used in directed energy deposition of the two additively manufactured walls.

\begin{tabular}{|c|c|c|}
\hline & Low power wall & High power wall \\
\hline Laser power (W) & 2300 & 4000 \\
\hline Travel speed (mm/s) & 8.5 & 10.6 \\
\hline Powder flow rate (g/min) & 18 & 23 \\
\hline Linear heat input (J/mm) & 271 & 377 \\
\hline Number of passes per layer & 5 & 5 \\
\hline Hatch spacing (mm) & 2.5 & 2.5 \\
\hline Z-step (mm) & 0.8 & 1.2 \\
\hline
\end{tabular}

Table 3. Elemental composition, in wt. \%, of the 304L prealloyed powder, the deposited material, and the annealed baseplate compared to the AISI standard.

\begin{tabular}{|c|c|c|c|c|c|c|c|c|c|c|}
\hline & $\mathbf{C}$ & $\mathbf{N}$ & $\mathbf{S i}$ & $\mathbf{M n}$ & $\mathbf{C r}$ & $\mathbf{N i}$ & $\mathbf{M o}$ & $\mathbf{C u}$ & $\mathbf{P}$ & $\mathbf{S}$ \\
\hline $\begin{array}{c}\text { AISI } \\
\text { standard }\end{array}$ & Max 0.03 & - & Max 1 & Max 2 & $18-20$ & $8-12$ & - & - & Max 0.045 & Max 0.03 \\
\hline Powder & 0.01 & 0.08 & 0.5 & 1.5 & 19.0 & 10.3 & 0.04 & 0.03 & 0.006 & 0.006 \\
\hline $\begin{array}{c}\text { Deposited } \\
\text { material }\end{array}$ & 0.01 & 0.09 & 0.56 & 1.42 & 18.94 & 9.90 & 0.01 & 0.04 & 0.018 & 0.008 \\
\hline $\begin{array}{c}\text { Annealed } \\
\text { baseplate }\end{array}$ & 0.02 & 0.04 & 0.46 & 1.26 & 18.25 & 8.02 & 0.07 & 0.13 & 0.035 & 0.006 \\
\hline
\end{tabular}


Table 4. Summary of mechanical properties and increase in ferrite number after tensile tests.

Values in the table are average \pm standard deviation, where $\mathrm{n}$ indicates the number of samples tested in each condition

\begin{tabular}{|c|c|c|c|c|c|}
\hline & \multicolumn{2}{|c|}{ Low power wall } & \multicolumn{2}{c|}{ High power wall } & Annealed \\
\cline { 2 - 5 } & $\begin{array}{c}\text { Longitudinal } \\
\mathbf{n = 1 1}\end{array}$ & $\begin{array}{c}\text { Transverse } \\
\mathbf{n = 7}\end{array}$ & $\begin{array}{c}\text { Longitudinal } \\
\mathbf{n = 1 0}\end{array}$ & $\begin{array}{c}\text { Transverse } \\
\mathbf{n = 8}\end{array}$ & $\begin{array}{c}\text { Baseplate } \\
\mathbf{n}=\mathbf{4}\end{array}$ \\
\hline Yield strength (MPa) & $337 \pm 29$ & $314 \pm 6$ & $277 \pm 27$ & $274 \pm 7$ & $265 \pm 9$ \\
\hline Tensile strength (MPa) & $609 \pm 18$ & $606 \pm 13$ & $581 \pm 20$ & $560 \pm 12$ & $722 \pm 14$ \\
\hline Elongation (\%) & $48.2 \pm 2.5$ & $56.4 \pm 5.8$ & $41.8 \pm 3.5$ & $50.5 \pm 6.7$ & $62.3 \pm 2.6$ \\
\hline$\Delta$ Ferrite number (FN) & $0.9 \pm 0.3$ & $1.3 \pm 0.4$ & $0.9 \pm 0.3$ & $1.0 \pm 0.3$ & $41.7 \pm 4.1$ \\
\hline
\end{tabular}

Table 5. Statistical information on grain size and grain morphology, as well as values used to determine the Hall-Petch relationship in stainless steel 304L produced by AM, in which $a$ and $b$ are the average lengths of major and minor axes, and $d$ is the relevant grain dimension.

\begin{tabular}{|c|c|c|c|c|c|c|}
\hline & \multicolumn{4}{|c|}{ Longitudinal } & \multicolumn{2}{|c|}{ Transverse } \\
\hline & \multicolumn{2}{|c|}{ Low power wall } & \multicolumn{2}{|c|}{ High power wall } & \multirow{2}{*}{$\begin{array}{c}\text { Low power wall } \\
-\end{array}$} & \multirow{2}{*}{$\frac{\text { High power wal }}{-}$} \\
\hline & Top & Bottom & Top & Bottom & & \\
\hline \multicolumn{7}{|c|}{ Grain size and morphology measurements } \\
\hline $\begin{array}{l}\text { Median of } \\
\text { grain area } \\
\left(\mathrm{um}^{2}\right)\end{array}$ & 1532 & 1149 & 1394 & 1329 & - & - \\
\hline $\begin{array}{c}\text { Mean of grain } \\
\text { area }\left(\mu \mathrm{m}^{2}\right)\end{array}$ & 5942 & 3247 & 7610 & 6278 & - & - \\
\hline $\begin{array}{c}\text { Average } \\
\text { aspect ratio }\end{array}$ & $2.0 \pm 0.9$ & $2.3 \pm 1.0$ & $2.8 \pm 1.5$ & $3.2 \pm 1.7$ & - & - \\
\hline $\mathbf{a}(\mu \mathbf{m})$ & 62 & 49 & 82 & 80 & - & - \\
\hline b $(\mu \mathbf{m})$ & 31 & 21 & 29 & 25 & - & - \\
\hline \multicolumn{7}{|c|}{ Values used in Hall-Petch relationship } \\
\hline d $(\mu \mathrm{m})$ & 31 & 21 & 29 & 25 & 55 & 81 \\
\hline $\begin{array}{c}\text { Average yield } \\
\text { strength } \\
\text { (MPa) }\end{array}$ & $325 \pm 10$ & $395 \pm 5$ & $241 \pm 1$ & $328 \pm 3$ & $314 \pm 6$ & $274 \pm 7$ \\
\hline
\end{tabular}


Table 6. Material properties for austenitic stainless steels used for calibration of kinetic grain growth model.

\begin{tabular}{|c|c|c|}
\hline Property & Value & Reference \\
\hline Peak temperature of SS316 (K), $\mathbf{T}_{\mathbf{p}}$ & 2035 & {$[60]$} \\
\hline Activation energy of SS316 (kJ/mol), $\mathbf{Q}$ & 197 & {$[61]$} \\
\hline Thermal conductivity of SS304L $(\mathbf{W} / \mathbf{m} / \mathbf{K}), \boldsymbol{\lambda}$ & 29 & {$[39]$} \\
\hline
\end{tabular}

